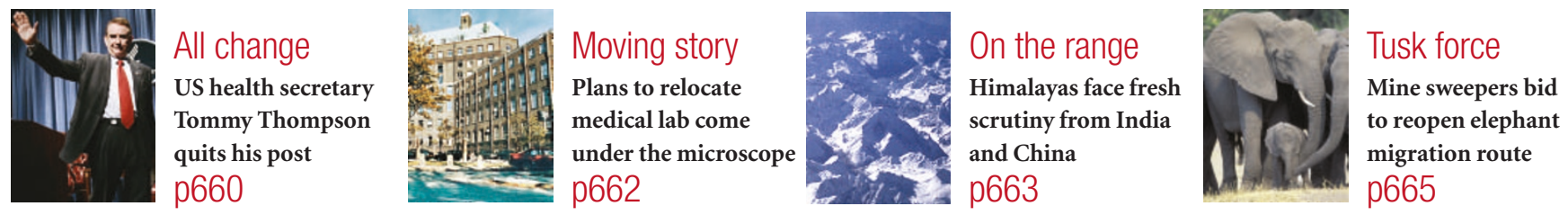

\title{
Curators bugged by museum's vision for insect collection
}

\section{Jim Giles, London}

Plans to move one of the world's premier natural history collections into new stateof-the-art premises are being resisted by researchers, who say that the relocation will hurt their ability to do their work.

By 2008, the mahogany cabinets that house the 28 million insect specimens at the Natural History Museum in London will be replaced by metal shelving and a sophisticated humidity control system in a striking new building at the museum's South Kensington site. Yet entomologists working on the collection say that the $\mathfrak{E} 65$-million (US\$125-million) building won't add much to the quality of science that they do.

According to a confidential two-page memo, a copy of which was given to Nature, the new facility will be too small and poorly equipped to deal with advances in information technology that are expected to transform entomology over the next decade. A lack of thorough consultation with scientific staff during the design process has meant that their need for space to work on the collection has been ignored for "reasons of aesthetics", says the memo, which was written by Quentin Wheeler, head of entomology at the museum, and sent on 1 December.

The dispute, in which many museum staff have complained publicly and privately about the relocation plan, is a setback for the museum's extensive expansion programme.

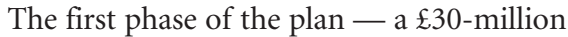
home for the zoology collection known as the Darwin Centre - opened in 2002, and attracted widespread praise for the way it opened up the museum's stores and research labs to public view. Senior staff say that Darwin Centre II (DCII) will do the same for the entomology collection, as well as providing a better environment for long-term storage.

At DCII, a cocoon-like structure, nestling inside an external glass frame, will house the specimens and provide views of the labs and stores. The samples will be preserved by excluding daylight, and pest control will be enhanced by keeping the temperature low. The current building is saturated with

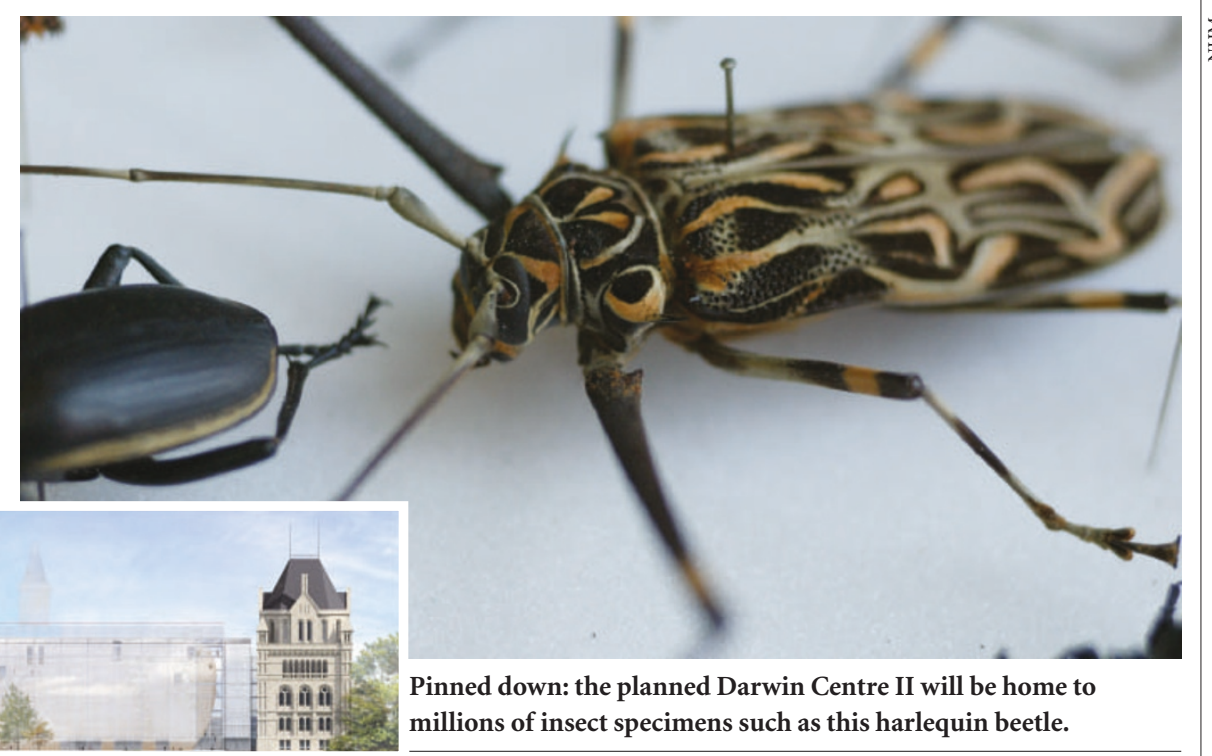

naphthalene, which provides good pest control but is also highly flammable.

Despite these advantages, some entomology researchers and curators describe the move as a "retrograde step" for research. They claim that there is not enough space set aside for several parts of the collection to be examined simultaneously in taxonomy projects, for example. Wheeler's memo also suggests that DCII cannot be adapted to provide space for new "cyber-infrastructure", such as facilities for specimens to be put under a microscope for viewing via the Internet.

\section{Under wraps}

In addition, the museum has been unable to confirm that all of the collection will stay in South Kensington. Researchers fear that some specimens will be stuck at a warehouse in Wandsworth, south London, which will be the collection's home while the current storeroom is demolished to make way for DCII. Some entomologists at the museum also allege that the museum is trying to suppress debate and stop them talking to the press. "The museum wants to say everything is rosy," says one member of the scientific staff, who declined to be identified. "It isn't."

Wheeler says that he has had several meetings with senior museum staff since writing his memo and is confident that the issues he raised can be addressed before the collection move begins in April. He adds that he now understands the design better and that he retracts his comment that it favours form over function. Acknowledging that access to collections maybeless easy in DCII, he says he has come round to the idea that the planned design is justified. "We need the best storage. That's at odds with the scientists' need for access," he says. "But you can't optimize both."

Such arguments might persuade entomologists that DCII is the right place for their collections, but researchers and curators are still anxious about the interim storage plans. The warehouse in Wandsworth has higher humidity levels than the museum, raising the chance that common pests such as booklice will attack the specimens. "We're working to bring the humidity down," says Wheeler."I'm confident it will be addressed."

Richard Lane, the museum's director of science, defends the DCII plans, saying that the critics are just accustomed to their way of working. "In many cases the argument is a surrogate for concern about change," he says. "People now live among the collections. In the new building, the offices will be separate and people are apprehensive about the change in their working environment." 